\title{
Improving Maternal Health: Maternal Morbidity and Mortality in Developing Countries
}

\author{
Article by Abimbola Patience Folorunso \\ Medicine, Texila American University, Nigeria \\ E-mail: folorunso.abimbola@yahoo.com
}

\begin{abstract}
Every minute a woman dies during labor or delivery. Approximately 529,000 women die from pregnancy related causes annually and almost all (99\%) of these maternal deaths occur in developing nations. The highest maternal mortality rates are in Africa, with a lifetime risk of 1 in 16; the lowest rates are in western nations (1:2800), with a global ratio of 400 maternal deaths per 100,000 live births. Causes of maternal mortality include postpartum hemorrhage, eclampsia, obstructed labor, sepsis, unsafe abortion, ectopic pregnancy, embolism etc. During the past years, increased recognition of these problems has led to the 'Safe Motherhood Initiative' by the World Health Organization in 1987, which was integrated into the goal of "Health for All in the year 2000." $45 \%$ of postpartum deaths occur within the first 24 hours and $66 \%$ occur during the first week. Of the estimated 211 million pregnancies, 46 million result in induced abortions. $60 \%$ of these abortions are unsafe and cause 68,000 deaths annually. With appropriate strategy and intensive implementation programs, some countries have made remarkable progress, not including many developing countries. Many developing nations face extreme challenges in the implementation of these strategies including lack of reliable data, shortage in human and financial resources, limited political commitment, pregnant women have minimal access to skilled labor and emergency care. Basic emergency obstetric interventions such as antibiotics. Oxytocins, anticonvulsants, manual removal of placenta and instrumental vaginal delivery are vital to improve the chance of survival.
\end{abstract}

Keywords: Maternal Health, Maternal Death, Maternal Morbidity, Ante natal Care, Emergency Obstetrics Care, Push and Pull factors, Brain drain

\section{Introduction}

Maternal health is the health of women during pregnancy, childbirth and 42 days after childbirth or postpartum period.

- Aims to reduce to minimum maternal morbidity and mortality

- Components

- Pre-conceptional care

- Antenatal care

- Intrapartum care (delivery services)

- Postnatal (postpartum) care

\section{Pre-conceptional care}

- Preventive services aimed at adequately preparing adolescent woman for next level of her reproductive period

- Services include

- Screening for diseases and genetic counseling

- Prevention of STI

- Prevention of drug abuse or alcoholism

- Prevention of unwanted pregnancy

- Immunisation

\section{Antenatal care}

- Goal is to reduce maternal and perinatal morbidity and mortality

- It should be goal-directed, client-oriented and evidence-based (focused ANC)

- It should be provided by skilled provider

The WHO (1999) defines maternal death as the death of a woman while pregnant or within 42 days 
DOI: $10.21522 / T I J M D .2013 .07 .01 . A r t 001$

ISSN: $2520-3118$

of termination of pregnancy, irrespective of the duration and site of the pregnancy, from any cause related to or aggravated by the pregnancy or its management but not from accidental or incidental causes.

A direct maternal death is one that results from obstetric complications of pregnancy, childbirth and the postpartum including interventions as well as omissions or incorrect treatments. For example, a death caused as a result of severe bleeding, hypertension, CS complications etc.

An indirect maternal death is one that results from a previously existing disease or from a disease that developed during pregnancy that may be aggravated by the physiological effects of pregnancy. For example, death due to the worsening of existing heart conditions or infectious diseases.

Pregnancy-related death: This is the death of a woman while pregnant or within 42 days of termination of pregnancy irrespective of the cause of death.

Late maternal death: This is the death of a woman from direct or indirect Obstetrics causes, more than 42 days but less than one year after termination of pregnancy.

\section{Extent of maternal mortality}

- Risk of death in a single pregnancy or live birth

- Fertility rate i.e. the number of pregnancies or birth that are experienced by women of reproductive age in a given population.

\section{Measures of maternal mortality}

1. Maternal Mortality Ratio (MMR): The number of maternal deaths during a given time period per 100, 000 live births during the same time period.

$$
\text { Maternal mortality rate }=\frac{\begin{array}{c}
\text { Number of deaths from puerperal } \\
\text { causes in a given year and population }
\end{array}}{\begin{array}{c}
\text { Total number of live births in the same } \\
\text { period }(1 \text { year }) \text { and population }
\end{array}} \times 100,000
$$

2. Adult lifetime risk of maternal death: The probability that a 15 -year-old woman will die eventually from a maternal cause. Takes into account the MMR and the total fertility rate.

3. Proportion of deaths among women of reproductive age that are due to maternal causes (PM): Number of maternal deaths in a given time period divided by the total deaths among women aged $15-49$ years.

Globally, maternal mortality rate has fallen by $45 \%$ between 1990 and 2013.

Sub-Saharan Africa accounts for $62 \%$ deaths followed by Southern Asia with $24 \%$ of deaths. That is $86 \%$ of all maternal deaths worldwide.

The WHO categorized MMR as,

- Extremely high $>1000$

- Very high 500-999

- High 300-499

- Moderate 100-299

- Low $<100$

Sub-Saharan Africa has a very high MMR.

One-third of all global maternal deaths are India at $17 \%$ and Nigeria at $14 \%$ due in part to their large populations.

\section{Risk of maternal death}

- Globally: 1 in 90

- Developed countries: 1 in 3700

- Developing countries: 1 in 52

- Sub-Saharan Africa: 1 in 38

- Chad: 1 in 15

- Somalia: 1 in 18 


\section{Maternal deaths attributed to HIV}

Volume 7, Issue 1, Apr 2019

Proportion of maternal deaths attributed to HIV of $10 \%$ or more;

- South-Africa - $41 \%$

- Botswana - $24 \%$

- Swaziland - $19 \%$

- Zambia - $15 \%$

- Lesotho $-15 \%$

- Namibia - $14 \%$

- Mozambique - $13 \%$

- Gabon-10\%

\section{Causes of death}

From medical perspective, women die from complications that happen during and following pregnancy and childbirth.

\section{Causes of maternal death in the world by percentage}

- Severe bleeding - $27 \%$

- Preexisting conditions - $28 \%$

- Blood clots/embolism - 3\%

- Abortions complications - $8 \%$

- Infections - $11 \%$

- Pregnancy induced hypertension - $14 \%$

- Obstructed labour and others - 9\%

The major complications that account for about $75 \%$ of all maternal deaths are severe bleeding, mostly after birth.

\section{WHO Estimates on Nigeria's Maternal Mortality for 2013}

- 287,000 maternal deaths globally

- India contributed 50,000 - ranked $1^{\text {st }}$

- Nigeria contributed 40,000 deaths $(14 \%)$ - ranked 2nd

- 110 Nigerian women died daily

- 5 die per hour, from pregnancy-related causes.

- Nigeria accounts for $14 \%$ of the world's maternal deaths while representing only $2 \%$ of the world's population, most of which are preventable (WHO 2012) 
DOI: 10.21522/TIJMD.2013.07.01.Art001

ISSN: $2520-3118$

Table 1, Showing Trend in Causes of Maternal Mortality in Nigerian Hospitals [1970 - 2015]

\begin{tabular}{|c|c|c|c|c|c|c|}
\hline \multirow[b]{2}{*}{$\begin{array}{l}\text { Hospital [Year of } \\
\text { Publicationa] }\end{array}$} & \multicolumn{4}{|c|}{ Between 1970-1975 } & \multirow{2}{*}{$\begin{array}{l}1988 \\
\text { JUTH }[1988)\end{array}$} & $2012-2013$ \\
\hline & $\begin{array}{l}\text { LUTH } \\
{[1978]}\end{array}$ & UCH $[1974]$ & $\begin{array}{l}\text { Calaber \& Abia } \\
\text { [1973] }\end{array}$ & $\begin{array}{l}\text { Keduna } \\
\text { [1975) }\end{array}$ & & $\begin{array}{l}42 \text { Tertiary Hospitals } \\
\text { [2015] }\end{array}$ \\
\hline Authur & Okoisor & Ojo \& Sevege & Waboso & Blechandren & Wright \& Disu & Oledepo et al. \\
\hline Number of Deaths & 38 & 105 & 116 & 155 & 95 & 998 \\
\hline Pre-/Eclampsia & $44.70 \%$ & $3.80 \%$ & 0 & $17.40 \%$ & $6.30 \%$ & $29 \%$ \\
\hline Heemorrhage & $26.30 \%$ & $3.80 \%$ & $25 \%$ & $25.20 \%$ & $31.50 \%$ & $24.40 \%$ \\
\hline Obstruted Labour & $15.70 \%$ & $3.80 \%$ & $10.40 \%$ & $23.90 \%$ & 0 & $2.50 \%$ \\
\hline Anaesthetic Death & $7.90 \%$ & $3.80 \%$ & 0 & $2.60 \%$ & $2.10 \%$ & - \\
\hline Intestinal Obstruction & $2.60 \%$ & - & $1.70 \%$ & - & $\cdot$ & . \\
\hline Infective Hepatitis & $2.60 \%$ & - & $35.50 \%$ & - & - & - \\
\hline Severe Anaemia & - & $18.60 \%$ & $1.70 \%$ & $4.50 \%$ & $11.60 \%$ & - \\
\hline Acute Hepatic Fe'lure & - & $12 \%$ & 0 & $7.10 \%$ & $15.80 \%$ & - \\
\hline Septiceemia & - & $7 \%$ & $5.10 \%$ & $9.70 \%$ & $16.80 \%$ & $14.20 \%$ \\
\hline Hemoglobinopethies & . & $4.40 \%$ & $1 \%$ & - & $1.10 \%$ & - \\
\hline Ruptured Uterus & . & $\cdot$ & $14.00 \%$ & . & $13.70 \%$ & - \\
\hline Tetanus & . & - & $3,0 \%$ & - & - & - \\
\hline Cerdiac Disease & . & - & $1.70 \%$ & - & - & - \\
\hline Respiretory Infection & - & - & $1.70 \%$ & $3.20 \%$ & $\cdot$ & $\cdot$ \\
\hline Pulmonary Embolism & - & . & $1 \%$ & - & $1.10 \%$ & $2.40 \%$ \\
\hline Meningitis & - & . & 0 & $2.60 \%$ & - & - \\
\hline Gestroenteritis & . & . & 0 & 3.2 & . & . \\
\hline Abortions & - & - & - & - & - & $7.80 \%$ \\
\hline $\begin{array}{l}\text { Non-Obstetric } \\
\text { [Indirect Ceuses] }\end{array}$ & - & - & - & - & - & $19.60 \%$ \\
\hline
\end{tabular}

Table 2, Showing Pattern of Causes of Maternal Mortality/Near-miss in Nigeria Compared to those in USA

\begin{tabular}{|c|c|c|c|}
\hline & \multicolumn{2}{|c|}{ Nigeria: 42 Tertiery Hospitals } & USA \\
\hline Author & \multicolumn{2}{|c|}{ Oledepo OT et al } & \multirow{2}{*}{$\begin{array}{l}\text { Donna Montalto } \\
2013 \text { (2006-08) }\end{array}$} \\
\hline \multirow[t]{2}{*}{ Year of Publication } & $2015[2012-13]$ & 2015 & \\
\hline & Maternal near-Miss & Maternal Deaths & Maternal Deaths \\
\hline Number of Ceses/MMR & 1,451 & 998 & $M M R=14.5$ \\
\hline Obstetric Heemorrhage & 4996 & 24.4036 & $11.50 \% 6$ \\
\hline Pregnancy-related Infections & $2.50 \%$ & $14.20 \%$ & $11.10 \%$ \\
\hline Abortive Outcome & $18.20 \% 6$ & $7.80 \%$ & $?$ \\
\hline Hypertensive Disarders & $20.50 \%$ & $29 \%$ & $10.50 \%$ \\
\hline Dystacia & $3.10 \%$ & $2.50 \%$ & 0 \\
\hline Embolism & $0.10 \%$ & 2.4036 & $5.90 \% 6$ \\
\hline [Non-Obstetric [Indirect] & [6.5\%] & [19.6\%] & \multirow[t]{2}{*}{ [55.5\%] } \\
\hline Complications] & & & \\
\hline HIN/AIDS & $0.50 \%$ & $4.10 \%$ & - \\
\hline Malaria & $0.60 \%$ & $1.20 \%$ & - \\
\hline Anaemia & $3.20 \%$ & $6.30 \%$ & - \\
\hline Heart Disease & $1.20 \%$ & $2.00 \%$ & $12.40 \%$ \\
\hline Pulmonary Disease & $0.30 \%$ & $0.80 \%$ & $?$ \\
\hline Renal Disease & $0.30 \%$ & $0.40 \%$ & $?$ \\
\hline Hepatic Disease & $0.10 \%$ & $0.90 \%$ & - \\
\hline Cancer & $0 \%$ & $1.10 \%$ & $?$ \\
\hline Cerdiavescular Disease & - & - & $14.60 \%$ \\
\hline Non-Cardiovascular Disease & - & - & $11.90 \%$ \\
\hline Thrombotic Pulmonary Embolism & - & - & 10.3036 \\
\hline Cerebrovescular Accident & - & - & $5.70 \%$ \\
\hline Aneesthetic Complications & $?$ & $?$ & $0.60 \% 6$ \\
\hline
\end{tabular}




\section{The four- delay model}

1. The delay in recognizing danger or need to seek care which is due to;

- Ignorance

- Low level of awareness

2. The delay in deciding to seek care is due to;

- The low status of women

- Poor understanding of complications and risk factors in pregnancy and when to seek medical help.

- Previous poor experience of healthcare.

- Financial implications.

3. The delay in reaching care is due to;

- Distance to health centres and hospitals

- Availability of and cost of transportation.

- Poor roads and infrastructure.

- Geography e.g mountainous terrain, rivers.

4. Delay in receiving adequate healthcare due to;

- Poor facilities and lack of medical supplies.

- Inadequately trained and poorly motivated medical staff.

- Inadequate referral systems.

\section{How to address these delays}

1. The delay in recognizing danger or need to seek care: Community health education and sensitization on birth preparedness and complication readiness plan.

2. The delay in deciding to seek care: provide communities (men and women) with information on pregnancy, childbirth and newborn healthcare so they know when to seek medical help. Facilitate income generation schemes for women to enable them become financially independent and empowered to make decisions about their own sexual and reproductive health and to become future leaders.

3. The delay in reaching care: improving access to healthcare with the provision of health centres in rural and remote areas as well as outreach healthcare workers visiting villages to provide care. Build waiting houses next to health centers for expectant mothers to stay in before their due date so when they go into labour assistance is on site. Provision of motorbike ambulances for mountainous terrain to improve access to health centers.

4. Delay in receiving adequate healthcare: Training local midwives who will remain in rural areas when qualified, trained nurses, doctors and healthcare professionals to provide safe births now and for future generations. Ensuring health centres are suitably equipped to provide safe deliveries and improving referral systems between health centers and hospitals.

\section{What is needed to reduce maternal mortality}

\section{Local}

- Functional health system; strengthening the health system, health system reform

- Strong country leadership.

- Maternal death review/audit

\section{Global}

- Smart, innovative global health investment.

- Global polity movement for coordination to continue to accelerate progress toward MDG5.

Major causes of maternal death in developing world

- Hemorrhage

- Hypertensive disorders (preeclampsia and eclampsia)

- Prolonged/obstructed labor

- Infection/sepsis

- Unsafe abortion

- HIV/AIDS

In the developed world, as exemplified by the United States, hemorrhage, hypertensive disorders of 
DOI: $10.21522 / T I J M D .2013 .07 .01 . A r t 001$

ISSN: $2520-3118$

pregnancy, infection and sepsis still account for slightly more than one-third of the deaths. But Obstructed labor, unsafe abortion and HIV/AIDS are not in the top ten causes, rather chronic health conditions like Cardiovascular disease and Cardiomyopathy account for almost as many as those other causes combined. Diabetes is not an exception.

Diabetes is a chronic condition that increases maternal mortality risk.

Obesity is also a risk factor for uterine atony which is also increasing and is a risk factor for postpartum hemorrhage.

As BMI increases, the risk of chronic hypertension increases dramatically.

Advanced maternal age is a potent risk factor for maternal mortality.

Hypertension increases in proportion to age.

\section{Primary prevention of maternal deaths}

Would there be any maternal deaths in the absence of pregnancies? Of course not. However, the prevention of unwanted pregnancies actually is a primary preventive card for maternal mortality worldwide.

Preconception counseling is also a primary prevention. A woman should be healthy before conceiving although, that's not always the case.

\section{Secondary prevention of maternal deaths}

Early detection e.g for pre-eclampsia and eclampsia.

\section{Most common preventable errors}

- Failure to obtain adequate control of blood pressure in hypertensive women.

- Failure to diagnose and treat pulmonary edema in women with pre-eclampsia.

- Failure to pay attention to vital signs after C-Sections.

- Hemorrhage following C-S.

\section{Healthcare workforce shortages: maldistribution and migration}

Healthcare work force shortages: over 275,000 women die each year from childbirth and over 3 million infants may not survive beyond the first month of life.

\section{Interventions}

- Well-equipped health facilities that are accessible and affordable for women.

- Health professionals that are well trained and experienced in maternal and infant health.

In the United States, $91 \%$ of women are attended by Obstetricians or family physicians at the time of delivery, while $9 \%$ are attended by midwives and less than $1 \%$ of women in the United States deliver without the help of a trained health provider.

But in many developing countries, there is an extreme shortage of doctors such as Obstetricians and nurses who provide most of the healthcare including delivering babies.

In Nigeria, according to UNICEF, a woman dies every 10 minutes due to pregnancy complications and child births, that is about 144 women in a day and about 50, 000 women in a year. Only $42 \%$ of births are attended to by skilled medical practitioners.

How bad is the healthcare worker shortage? Globally, it's estimated to be 4.3 million.

Why do we have shortage? The shortage of healthcare workers is both a function of increased need and decreased supply.

\section{Increase need includes}

- Aging population

- Expanding population

- Increased incidence of chronic diseases

- Emerging epidemics (HIV/AIDS)

\section{Decreased supply includes}

- Under investment in healthcare worker pre-service education.

- Lack of health system planning.

- Lack of information about needs.

- Poor retention of workers. 
- Migration.

- Maldistribution of health workers.

\section{Maldistribution and migration (brain drain)}

Brain drain refers to departure of educated or professional people from one country, economic sector or field to another, usually for better pay or living conditions. Worldwide, WHO estimates that there are around 60 million healthcare workers, and like any other group of professionals, they tend to migrate to areas where working conditions are best.

Many health workers enjoy living in urban areas where there are good schools for their children, educational opportunities for themselves, increased availability of jobs for their spouses, better housing etc.

Thus, many rural areas may be under served because they are hard to reach, poverty stricken and lack the amenities of cities.

Another problem that contributes to maldistribution is the migration of skilled health workers from developing countries to more developed countries such as Europe and the United States. For example, A 1993 report from the United Nations Development Programme indicates that more than 21,000 Nigerian doctors are working in the United States while Nigeria suffers from a shortage of doctors.

\section{Why do they migrate? Push factors and pull factors}

Push factors: factors in the home country or rural areas that encourage health workers to migrate. These include;

- Poor Nurse to population ratio.

- Wages

- Socioeconomic context (social amenities)

- Lack of educational opportunities.

- HIV/AIDS prevalence

- Risk of occupational exposure

- Lack of commodities, resources.

- Lack of career opportunities

- Poor working conditions and management (corruption, limited resources and equipment).

- Political instability, war, violence.

Pull factors: factors in the urban areas or host country that pull health workers towards these areas. These include:

- High income country

- Greater career opportunities

- Recruitment by destination countries

- Better resources

- Lower patient to nurse ratios

- Educational opportunities

- Better opportunities for family (schooling, living conditions etc.,)

\section{Solutions}

There is No One solution.

- Improving salaries and benefits is critical.

- Working and living conditions must be at good standard to encourage workers to relocate or remain in underserved areas.

- Education, training and professional development opportunities.

- Good supervision and management.

- Social recognition.

- Bonding and mandatory service.

- Payment systems.

- Increased salaries and financial benefits for rural workers e.g hardship allowance.

- Rural recruitment and training.

- Increased production of health personnel with compulsory public service. 


\section{Interventions Employed to Reduce Maternal Mortality in Nigeria}

- Maternal and Perinatal Death Surveillance Response(MPDSR)

- Mid wife Service Scheme

- National Health Insurance Scheme

- Subsidy Reinvestment and Empowerment Program.

- Saving One Million Lives Initiative(P4R)

- National Vaccine Scheme

- Awareness creation / community mobilization
- Fortification Pre- Pregnancy (Folic acid)

- Task sharing

- Malaria elimination program -Malaria in Pregnancy

- Integration( District Health Information System/IDSR)

- Focused Antenatal Care

- PMTCT of HIV

- Family Planning

- Post-abortion Care

\section{Conclusion}

In conclusion, every woman should enjoy optimal health at Pre-conception, during Antenatal, Intrapartum and Postnatal period. Every pregnant woman should know and be able to recognize possible danger signs in her and the unborn child during pregnancy and when to seek prompt help from a qualified health care provider. The present statistics of maternal morbidity and mortality are unacceptably high in developing countries and all hands have to be on deck to ensure that these preventable deaths are brought to a halt and guarantee the health of women.

\section{Recommendations/way forward}

1. Leadership and Governance; accountability in governance, taking ownership and providing leadership in the health sector

\section{Human Resources for Health:}

\section{Task shifting vs task sharing}

Task shifing- A process in which specific tasks are moved, where appropriate, to health workers with shorter training and fewer qualifications.

Task sharing- Emphasizes a knowledge-based requirement for delegated roles and responsibilities and underscores the involvement of health professional collaboration when providing care.

Task shifting focuses on the delegation of duties. Task sharing incorporates work place strategies that build upon the collective input of the health unit or health team.

\section{Health-care service delivery}

\section{Emergency Obstetrics Care - EMOC}

\section{Signal functions include two types: Basic EMOC}

\section{Comprehensive EMOC}

These signal functions are key medical services used to treat complications that cause majority of maternal deaths. The signal functions are indicators of the level of obstetric care being provided in a particular health facility. In addition, the existence of some services is implied within a single signal function e.g. if a facility is performing the signal function of a Cesarean Section, it is implied that such facility also provides adequate anesthesia. The EMOC signal functions do not comprise a comprehensive list of every maternal and newborn service that a facility should provide. Routine 
services that every woman in labor should receive include labor monitoring with a partograph - a tool that tracks labor progress over time.

Active management of $3 \mathrm{rd}$ stage of labor, which include the timely administration of drugs to prevent postpartum hemorrhage.

And infection prevention measures.

More general requirements include service availability. 24/7 cares with enough skilled health workers, basic infrastructure such as electricity, clean water, a latrine and a system of referral to higher level care.

So, the basic EMOC signal functions currently include

- Administer parenteral antibiotics

- Administer parenteral anticonvulsants (to prevent seizures in the event of pre-eclampsia)

- Administer uterotonic drugs (help uterus contract and treat prolonged labor or postpartum hemorrhage)

- Perform manual removal of the placenta.

- Remove other retained products.

- Perform assisted vaginal delivery (birth by way of vacuum extraction or obstetrical forceps) partially useful when a foetus is very low in the maternal pelvis but not able to be delivered with maternal pushing efforts alone.

- Perform basic neonatal resuscitation (with oxygen bag and mask when a newborn is experiencing respiratory problems following delivery).

\section{Comprehensive EMOC signal functions}

- All basic EMOC functions

- Perform surgeries e.g Caesarean Sections, surgical management of ectopic pregnancy and other obstetric complications.

- Perform blood transfusions.

Specific obstetric complications that can be treated by the EMOC signal functions either alone or combined include:

- Obstetric hemorrhage

- Pre-eclampsia/eclampsia

- Prolonged or Obstructed labor

- Ruptured uterus.

- Postpartum sepsis

- Complications related to abortion (sepsis, hemorrhage or intra-abdominal injury)

- Ectopic Pregnancy

- Fetal and newborn distress.

We cannot forget about the newborns, so Emergency neonatal care includes:

- Administration of antibiotics to mother in cases of preterm labor.

- Administration of corticosteroid drugs for preterm labor to help for lungs maturity.

- Alternative feeding methods for premature, very small babies.

- Injectable antibiotics for neonatal sepsis.

- Intravenous fluids.

\section{Medicines and technologies/commodities}

Medicines, Technologies and Commodities that are germane to managing, maintaining and improving maternal health should be readily and affordably available to progressively reduce maternal morbidity and/or mortality particularly in developing countries.

UNITED NATIONS PROCESS INDICATORS FOR MONITORING EMOC

\section{Availability}

- Are there enough health facilities with the capacity to provide EMOC?

- Minimum of one comprehensive EMOC facility and 5 basic EMOC facilities per 500,000 population.

- Population $\div 500,000=$ over all minimum number of EMOC facilities. 
DOI: $10.21522 / T I J M D .2013 .07 .01 . A r t 001$

ISSN: $2520-3118$

\section{Geographical distribution}

- Are the existing EMOC facilities both adequately and equitably distributed?

- Minimum of one comprehensive EMOC facility and 5 basic EMOC facilities per 500,000 population. Calculated the same as the first except it takes into consideration the geographical distribution of EMOC by using sub national areas of study rather than region/country.

\section{Proportion of births in EMOC facilities.}

- Are enough women using care?

- Minimal acceptable standard is locally defined, based on proportion of births that occur in health facilities currently and national/ subnational goals.

- Calculated by dividing the number of women registered as giving birth in an EMOC facility by an estimate of all live births in the area.

\section{Proportion of women with major obstetric complications who are treated in EMOC facilities}

- Are the right women using this care?

- Goal is $100 \%$ of women with a major direct obstetric complication to be treated in an EMOC facility. Calculated by dividing the number of women treated in an EMOC facility over a specific period of time by expected number of women with a major complication.

\section{Proportion of all births by CS}

- Estimated proportion of births by CS is no less than $5 \%$ or more than $15 \%$.

- Calculated by dividing number of CS performed in EMOC facilities during a specific period (for any reason) by expected number of live births.

7. Proportion of women with a major direct obstetric complication who received care in an EMOC facility and who died prior to discharge.

- Is the quality of maternal health services adequate? goal is $<1 \%$

- Calculated by dividing the number of women dying from a major direct obstetric complication in an EMOC facility during a specified period by the number of women who were treated for all direct obstetric complications.

8. Proportion of births that result in an intrapartum fetal death or an early newborn death in an EMOC facility.

- Is the quality of care for fetuses and newborns sufficient?

- Calculated by dividing sum of intrapartum fetal deaths and newborn deaths that occur within 24 hours of birth in an EMOC facility during a specified period by the number of women who gave birth in that same facility during the same period.

\section{Proportion of maternal deaths from indirect obstetric causes in EMOC facilities.}

- No standard can be set

- Calculated by dividing all maternal deaths due to indirect causes in EMOC facilities in a specified period by all maternal deaths occurring in the same facilities in the same period.

\section{Acknowledgements}

1. Oladapo Shittu, Professor of Obstetrics \& Gynaecology.

2. Ahmadu Bello University Teaching Hospital, Zaria, Nigeria.

3. Dr Michael S. Oguntoye, MBBS (Zaria), MPH (Ilorin), Cert Public Preparedness \& Vaccine Policy (Hopkins), MPH (FELTP, Zaria), FWACP. Director Primary Health Care \& Disease Control, Kwara State Primary Health Care Development Agency, Ilorin, Nigeria. 


\section{References}

Volume 7, Issue 1, Apr 2019

[1]. Maternity Worldwide (2015) why do Women Die in Childbirth in low-income Countries? Available at: http://www.maternityworldwide.org/the-issues/women-die-childbirth (Accessed 19 May 2018).

[2]. Population Reference Bureau (2001) Delivery Care is key for Maternal Survival: A Story of Two States in Nigeria. Available at:

http://www.prb.org/Publications/Articles/2001/DeliveryCareIsKeyforMaternalSurvivalAStoryofTwoStatesinNig eria.aspx (Accessed 19 May 2018).

[3]. United Nations Population Fund (2016) Maternal Health. Available at: http://www.unfpa.org/maternalhealth (Accessed 19 May 2018).

[4]. World Health Organization (2007) Maternal Mortality in 2005. Available at: http://www.who.int/whosis/mme_2005.pdf (Accessed 21 May 2018).

[5]. World Health Organization (2009) Monitoring Emergency Obstetric Care. Available at: https://www.unfpa.org/sites/default/files/pub-pdf/obstetric_monitoring.pdf (Accessed 19 May 2018).

[6]. World Health Organization (2015) Trends in Maternal Mortality; 1990-2015. Available at: https://www.unfpa.org/sites/default/files/pub-pdf/9789241565141_eng.pdf (Accessed 21 May 2018).

[7]. World Health Organization (2016) Maternal and Perinatal Health. Available at:

http://who.int/maternal_child_adolescent/topics/maternal/maternal_perinatal/en (Accessed 19 May 2018).

[8]. World Health Organization (2018) Maternal Mortality. Available at: http://www.who.int/news-room/factsheets/detail/maternal-mortality (Accessed 21 May 2018). 